\title{
La danza académica en Honduras
}

\author{
Sara Buck- Rodríguez \\ Bailarina y coreógrafa \\ Universidad de Honduras \\ Honduras \\ Recibido: 15 de julio 2019 \\ Aceptado: 20 de diciembre de 2019 \\ Doi: https://doi.org/10.15359/tdna.36-67.5
}

\section{Resumen}

Este artículo recorre la historia del Estudio Danzarte de Siguatepeque, y aborda algunos temas sobre el desarrollo de la danza académica en Honduras, su nexo con la danza costarricense y su proyección a la comunidad, considerando la danza como herramienta de educación individual y colectiva, como expresión artística desde Centroamérica.

Palabras clave: Historia, danza en Honduras, educación, artes en Centroamérica, Arte en América Latina

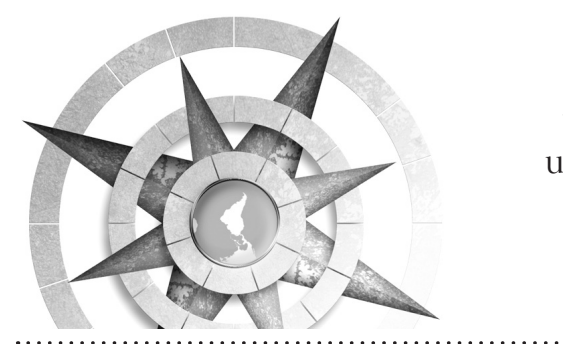

Este artigo passa em revista a história do Estudio Danzarte em Siguatepeque, e aborda algumas questões sobre o desenvolvimento da dança académica nas Honduras, a sua ligação à dança costa-riquenha e a sua projecção na comunidade, considerando a dança como um instrumento de educação individual e colectiva, como uma expressão artística da América Central.

This article reviews the history of Studio Danzarte in Siguatepeque, and addresses some issues about the development link with Costa Rican dance and its projection into the community, considering dance as a tool for individual and collective education, as an artistic expression from Central America. duras, Education, Arts in Central America, Arts in Latin America

\section{Resumo}


Palavras chave: Dança em Honduras, Educação, Artes na América Central, Artes na América Latina

\section{Un vistazo a la danza académica en Honduras}

La danza académica en nuestro país se inicia a finales de la década de los cincuentas y desde entonces han existido y continúan funcionando muchas instituciones dedicadas a formar bailarines en Ballet Clásico, Danza Contemporánea, Tap y Jazz, entre otros estilos de baile. Estas escuelas han sido de carácter gubernamental, privadas o semiautónomas, concentrándose la mayor actividad en Tegucigalpa y San Pedro Sula, y en otras ciudades como Siguatepeque,
Roatán, La Ceiba, Comayagua, El Progreso, Santa Rosa de Copán, Choluteca, Gracias y Danlí. (Anexo 1) Fueron dos instituciones, en Tegucigalpa, las que marcaron el inicio de la danza académica en Honduras, las cuales han tenido una influencia importante en todo el país.

\section{El Teatro Infantil de Honduras}

La primera academia de danza que existió fue El Teatro Infantil de Honduras, fundado en 1958 por la maestra Mercedes Agurcia Membreño, quien fungía como directora del Teatro Nacional.

Fotografía 1.

Mercedes Agurcia Membreño

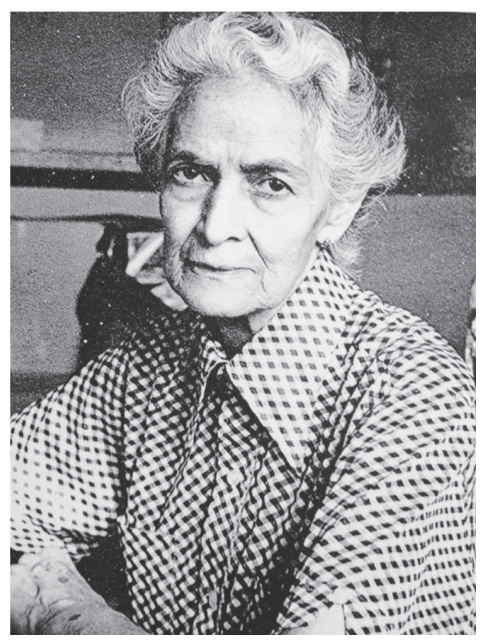


El TIH. montaba obras de teatro, canto y danza y presentó dos estrenos anuales desde su inicio hasta 1977, año en que su fundadora fue retirada de su cargo. Bajo su dirección el Teatro Infantil de Honduras realizó giras a Costa Rica, presentándose en el Teatro Nacional, y a México, en el Teatro de Bellas Artes.

En 1978 el TIH. fue absorbido por el entonces Ministerio de Cultura y Turismo y posteriormente cambió su nombre al que actualmente lleva: Escuela Nacional de Danza Mercedes Agurcia Membreño. Después de su fundadora, han sido directores: Jeanette Zacapa, Carmen Carías, Lesbia de Madrid, Judith Burwell, Mayra Enríquez, Luz Ernestina Carrasco, Norma Regina Zambrana, Claudia Zelaya, Roberto Silva y Cinthya Núñez.

\section{IHCI School of Ballet}

La siguiente institución fue el IHCI School of Ballet, fundado en 1966 por la norteamericana Judith Burwell, con el patrocinio del Instituto Hondureño de Cultura Interamericana. En 1968 se independizó y cambió su nombre a Escuela de Ballet Tegucigalpa.

Impartió Ballet Clásico, Danza Contemporánea y, eventualmente, danzas folclóricas de otros países. Se adscribió al entonces Ministerio de Cultura y Turismo en 1975 y se independizó nuevamente en
1979, convirtiéndose en el Ballet Tegucigalpa, bajo la dirección del profesor Roberto Silva. Funcionó hasta el año 1991.

De ambas instituciones egresaron muchos bailarines que continuaron con el legado de ambas maestras e hicieron efecto multiplicador y decidieron ejercer la danza como su profesión.

\section{Universidad Nacional Autónoma de Honduras (UNAH)}

Otro ente importante para la danza académica ha sido la Universidad Nacional Autónoma de Honduras, a través de su Departamento de Arte en la Facultad de Humanidades y Artes.

Dicho Departamento abrió la carrera de Arte de 1980 a 1988, graduando profesionales de arte con orientación en danza, música o teatro y actualmente está preparando los planes académicos para abrir la Licenciatura en Danza, bajo la dirección de Norma Zambrana, quien tiene una Maestría en Danza de la UNA, Costa Rica.

El Departamento de Arte imparte la clase de Iniciación a la Danza, como clase co-programática para estudiantes de diversas carreras; cuenta con su grupo representativo UNAH-Danza, que realiza presentaciones programadas por el Departamento o por invitaciones recibidas. 
Eventos de mucha importancia y participación centroamericana han estado a su cargo, como el Festival Interuniversitario Centroamericano de la Cultura y el Arte (Ficcua) en 2015 y los Juegos Deportivos Universitarios Centroamericanos (Juduca) en 2016.

Fotografía 2.

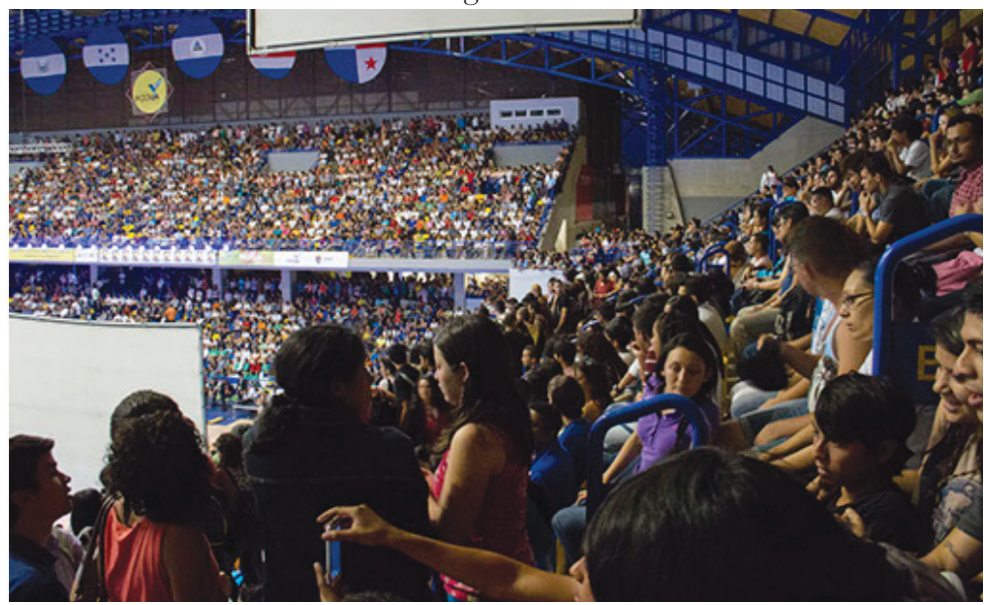

Fuente: Ficcua, 2015.

Fotografía 3.

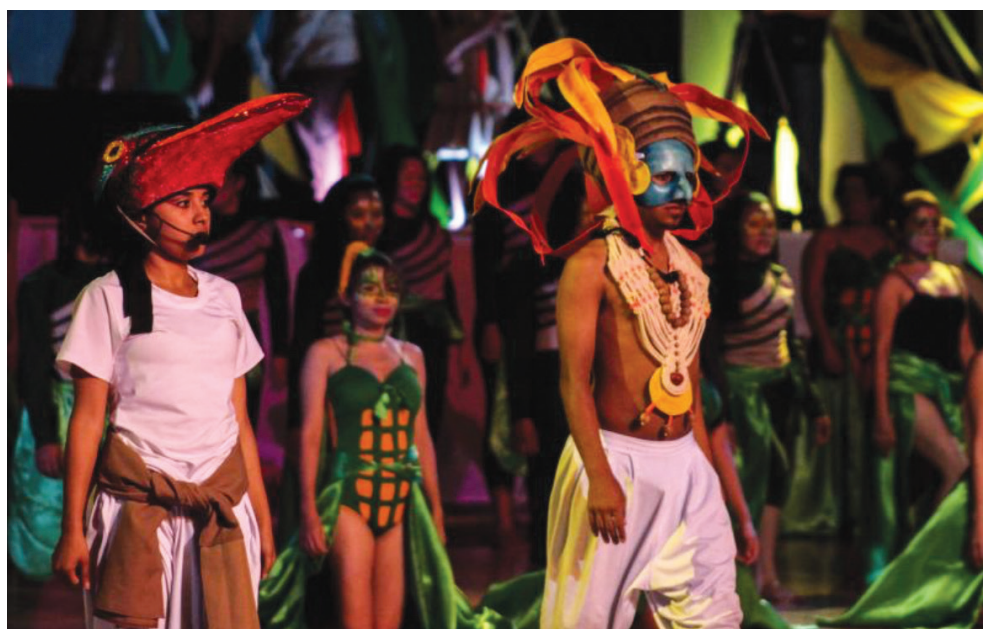

Fuente: Ficcua, 2015.

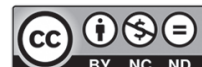

82 La danza académica en Honduras Sara Buck- Rodríguez

Licencia Creative Commons Atribución-No-Comercial

SinDerivadas 3.0 Costa Rica

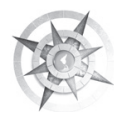


Fotografía 4.

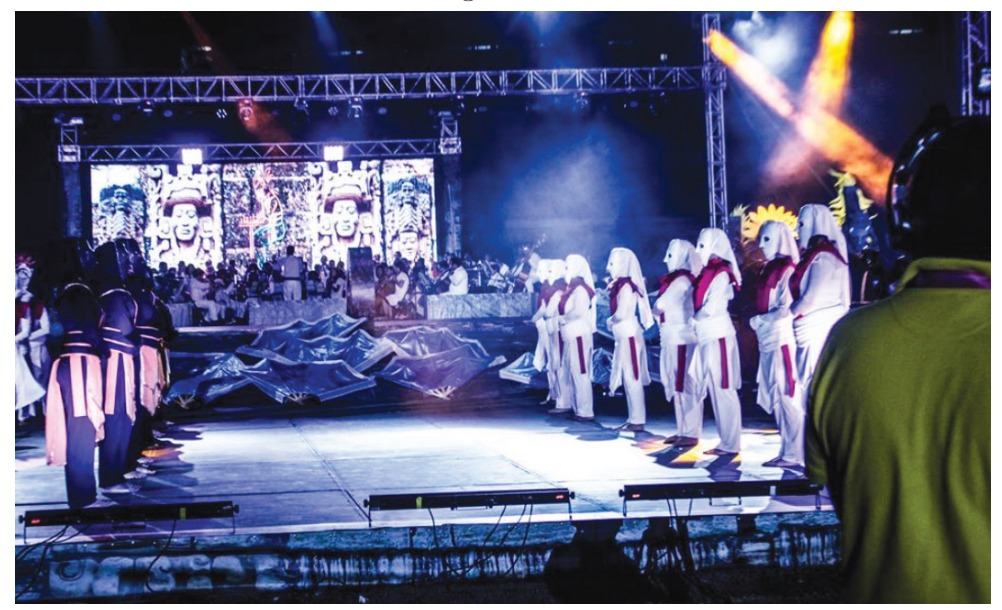

Fuente: Juduca, 2016.

Fotografía 5.

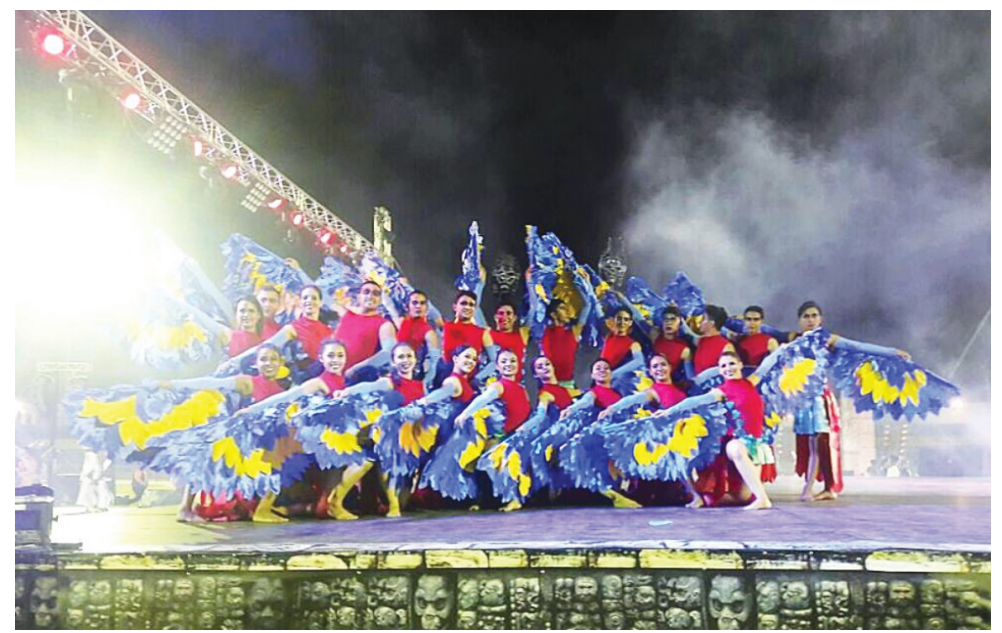

Fuente: Juduca, 2016. 


\section{Grupos y compañías, estatales e independientes}

La mayoría de las agrupaciones o compañías han tenido una vida relativamente corta; las razones son variadas: desde el factor económico y la falta de apoyo de instituciones públicas y/o privadas, hasta la falta de capacidades organizativas de los integrantes.
El intento más sólido de contar con una Compañía Nacional de Danza tuvo lugar durante el Gobierno de Carlos Roberto Reina. La agrupación se sostuvo de 1994 a 1996. Posteriormente, la modalidad se cambió a grupos que presentaban propuestas de espectáculos $\mathrm{y}$, de ser seleccionados, se presentaban con dicho espectáculo como si fueran la Compañía Nacional de Danza. Esta modalidad se mantuvo solo por un año.

Fotografía 6.

Compañía Nacional de Danza actuará en el V aniversario de Georgino Ballet Studio.

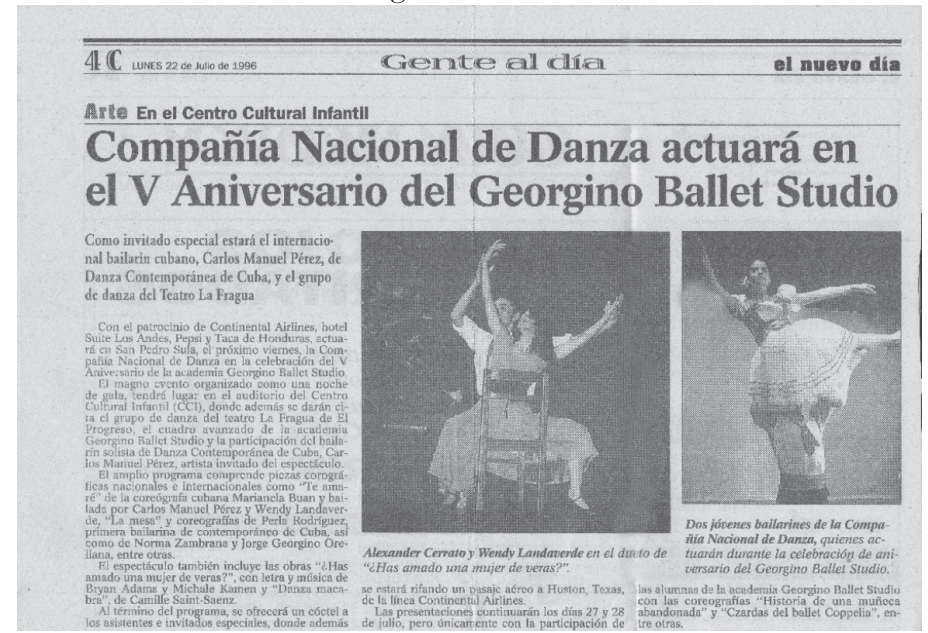

Fuente: Periódico Gente al Dia, 1996.

Hubo dos intentos más por consolidar la Compañía Nacional de Danza por iniciativa de particulares, pero no contando con el apoyo gubernamental, no duraron ni siquiera un año.
Se han formado varios grupos o compañías independientes, algunos cuantos aún permanecen, pero la mayoría han funcionado por pocos años e inclusive algunos meses. (Anexo 2).

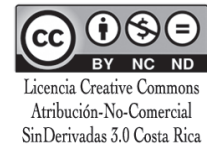

84 La danza académica en Honduras Sara Buck- Rodríguez

SinDerivadas 3.0 Costa Rica 
Nexos de la danza hondureña con la danza costarricense

La danza hondureña y la danza costarricense han estado unidas por eventos afortunados, pero también algunos muy lamentables.

De 1945 a 1957 Mercedes Agurcia Membreño ejerció como maestra en las Escuelas Porfirio Brenes y Marcelino García Flamenco. Fundó el Teatro Infantil de Costa Rica, montando innumerables trabajos. Recibió el Premio
Idoneidad de Arte de parte del Ministerio de Educación de Costa Rica, como reconocimiento por su labor educativa y artística. Al regresar de Costa Rica dirigió el Teatro Nacional en Tegucigalpa y fundó el Teatro Infantil de Honduras.

En 1965 el Teatro Infantil de Honduras invita al Ballet Tico de Coralia de Romero para presentarse en un evento a beneficio de la Asociación Hondureña Contra la Poliomielitis. El bus en que se trasladaban sufre una falla mecánica, y muchas de las integrantes del Ballet mueren trágicamente en el accidente.

Fotografía 7.

Afiche Ballet Tico.

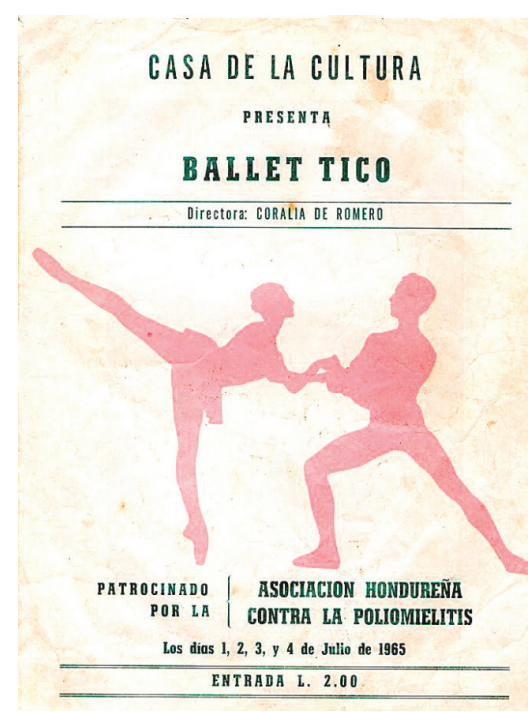

Fuente: 
En 1967 la Escuela Marcelino García M., en reconocimiento por su labor doFlamenco nombra su salón de actos cente y artística. con el nombre de Mercedes Agurcia

\section{Fotografía 8.}

Salón de Actos Mercedes Agurcia M.

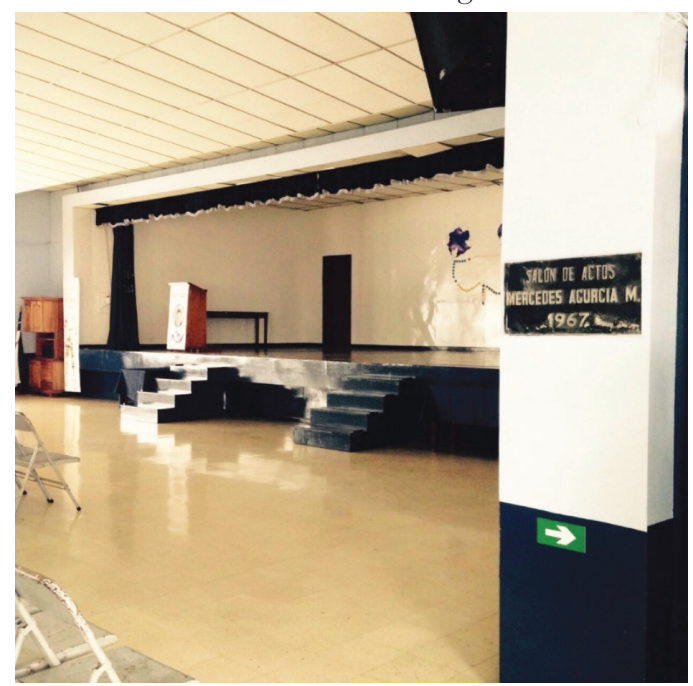

Fuente: Archivo personal de la autora

Fotografía 9.

Profesora Merceditas Agurcia y parte del personal docente, 1968.

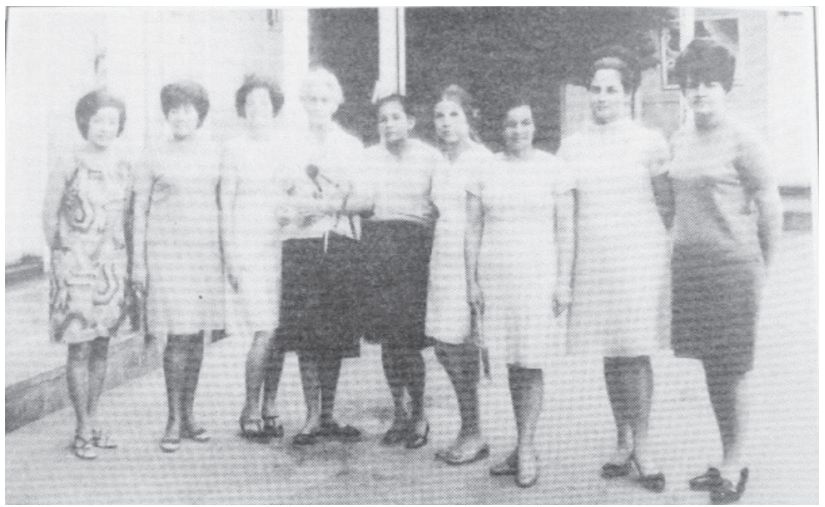

Fuente: N/A

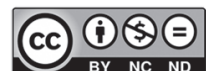

86 La danza académica en Honduras Sara Buck- Rodríguez 
En 1968 el Teatro Infantil de Honduras viaja a Costa Rica y presenta Aladino y la lámpara maravillosa.

\section{Fotografía 10.}

Grupo de Teatro Infantil de Honduras presenta su obra Aladino y la lámpara maravillosa en Costa Rica.

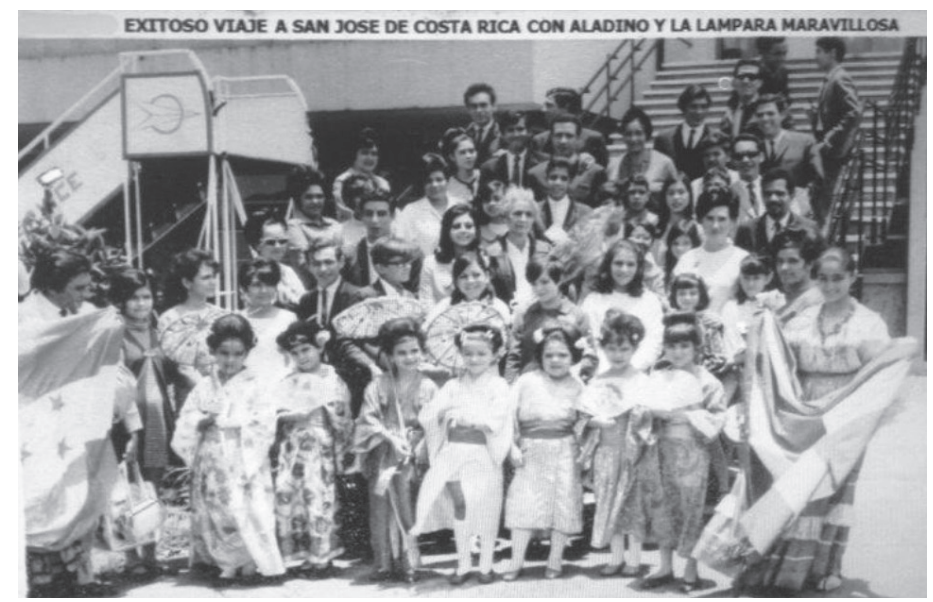

En 1975 el Teatro Infantil de Honduras viaja a Costa Rica para presentarse en el Teatro Nacional.

Fotografía 11.

Viaje a Costa Rica para presentación en el Teatro Nacional, 1980

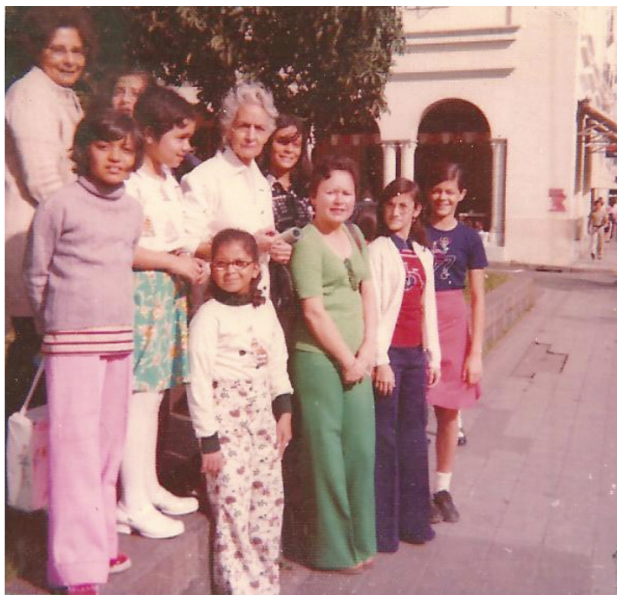


Desde 1980 a la actualidad, varios hondureños han realizado estudios en la carrera de Danza de la UNA, entre ellos Norma Zambrana (maestría), Sara Buck (bachillerato), Clarisa Flores (bachillerato) y Julio César Ciliezar, Toivo Oksat y Gerardo Chávez, quienes no concluyeron sus estudios.

Fotografía 12.

Norma Zambrano, Sara Buck y Gerardo Chávez.

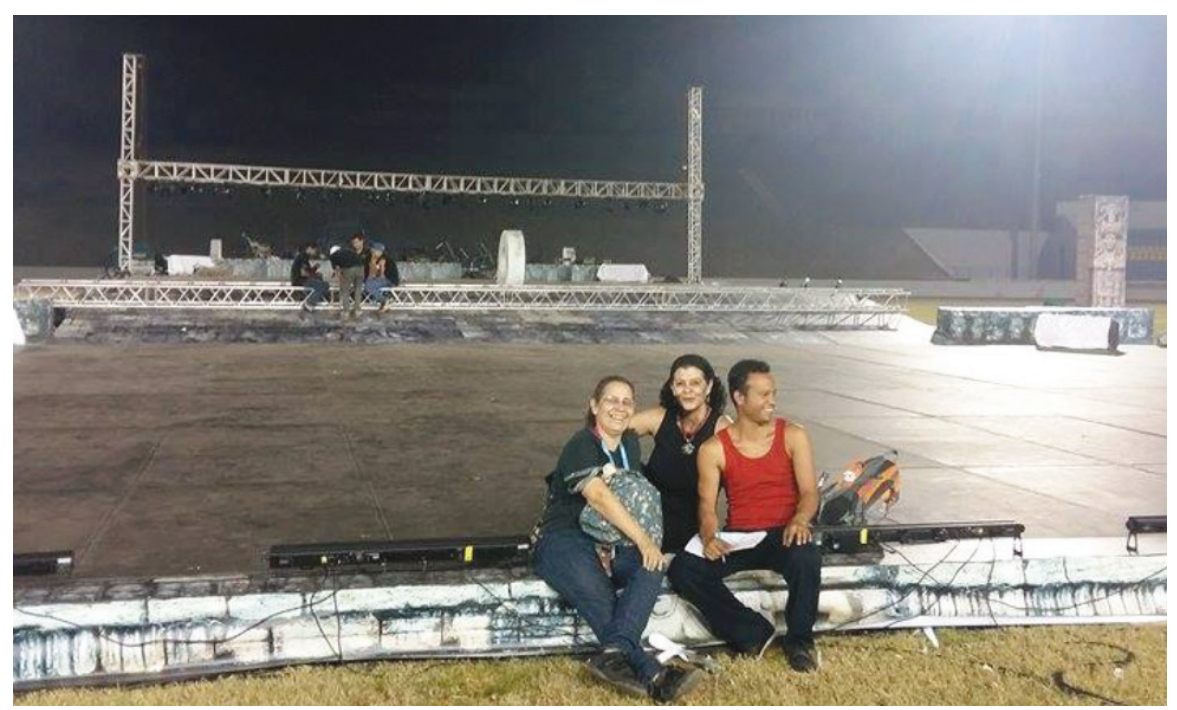

Fuente: Juduca, 2016.

Desde la década de los noventa han sucedido varios intercambios culturales, presentándose grupos de ambos países en el país hermano y Honduras ha recibido la visita de algunos maestros costarricenses, entre ellos Nandayure Harley, Rolando Brenes, Fito Guevara y Óscar Córdoba. 
Fotografía 13.

Danza libre, Espectáculo Isla. Dirección Nandayure Harley.

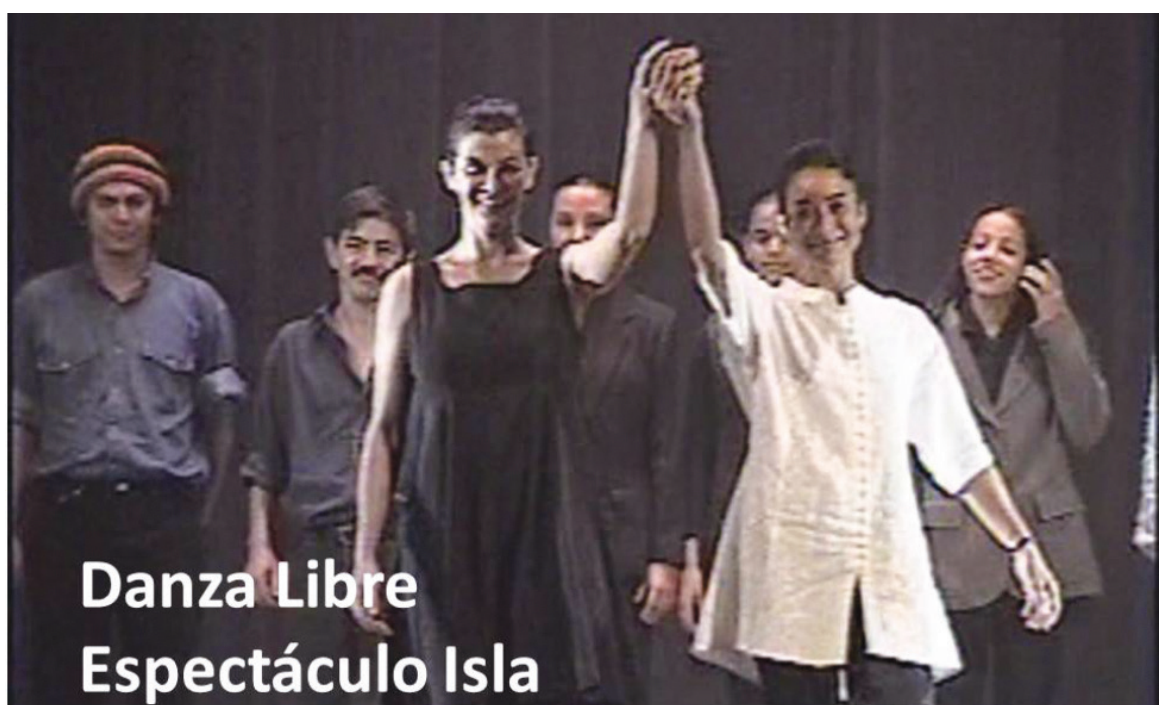

Fuente: Archivo de la autora

\section{Panorama general}

El desarrollo de la danza académica en Honduras ha sido un proceso difícil y los avances obtenidos se deben más al interés, trabajo y entrega de los amantes de la danza y en muy poca medida a algún apoyo privado o gubernamental.

Fue hasta 1975 que el Gobierno creó el Ministerio de Cultura y Turismo y aglutinó diversas instituciones existentes, como la Biblioteca Nacional, el Archivo Nacional, el Teatro Nacional y el Instituto Hondureño de Antropología e Historia.
Esta dependencia tuvo varios nombres según los gobernantes de turno y finalmente se denominó Secretaría de Cultura, Artes y Deportes. Esta se encargó de temas como políticas culturales, investigación, difusión, formación artística, patrimonio histórico y cultural y deportes.

El presupuesto de esta Secretaría siempre fue muy bajo en relación con los otros ministerios e insuficiente para cubrir las demandas de las entidades dependientes, mucho menos para emprender nuevos proyectos. A pesar de ello, la Secretaría buscaba incentivar al gremio artístico y anualmente otorgaba

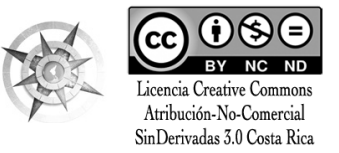


premios a las diversas disciplinas, como la Hoja de Laurel en Oro, el Premio Nacional de Arte Pablo Zelaya Sierra, el Premio de la Herencia Africana, el Premio Nacional al Voluntariado Cultural y el Premio Nacional de Narrativa Infantil y Juvenil.

De manera general, aunque limitada, la Secretaría de Cultura, Artes y Deportes cumplía su función; hasta que en el 2014 el nuevo presidente, Juan Orlando Hernández, decidió disolver la Secretaría para ahorrar en el presupuesto de la república y la degradó a dos direcciones ejecutivas, una de cultura y artes y la otra de deportes.

Este ha sido un gran retroceso y un golpe duro para el gremio cultural y el desarrollo del arte y de la cultura en nuestro país, pues las direcciones cuentan con menos presupuesto y menos injerencia política para fortalecer el desarrollo de las artes y del deporte.

\section{Las universidades privadas}

Las universidades privadas podrían jugar un papel muy importante en el desarrollo de las artes, sin embargo, solo algunas de ellas cuentan con grupos artísticos representativos.

Estos grupos no incluyen la danza y en general son constituidos por artistas que han sido formados en otros cen- tros, no en la propia universidad, y que obtienen beca debido a su talento. De esta manera, las universidades cumplen con algunos requisitos de carácter internacional que las hacen aparecer como promotoras del arte, lo cual es solo parcialmente cierto.

\section{Sara Buck en el contexto de la danza hondureña}

Inició sus estudios en Danza con la maestra Mercedes Agurcia en Tegucigalpa, continuó a nivel profesional graduándose de Bachiller en Danza, en la Universidad Nacional en Costa Rica. Ha recibido cursos con maestros de Estados Unidos, México, España, Canadá, Italia, Centroamérica, Brasil, Alemania, entre otros, y ha bailado en Honduras, Nicaragua, Costa Rica, El Salvador y México. Su trayectoria como bailarina, docente y coreógrafa ha sido de treinta y cinco años. 


\section{Fotografía 14.}

Sara Buck, bailarina hondureña.

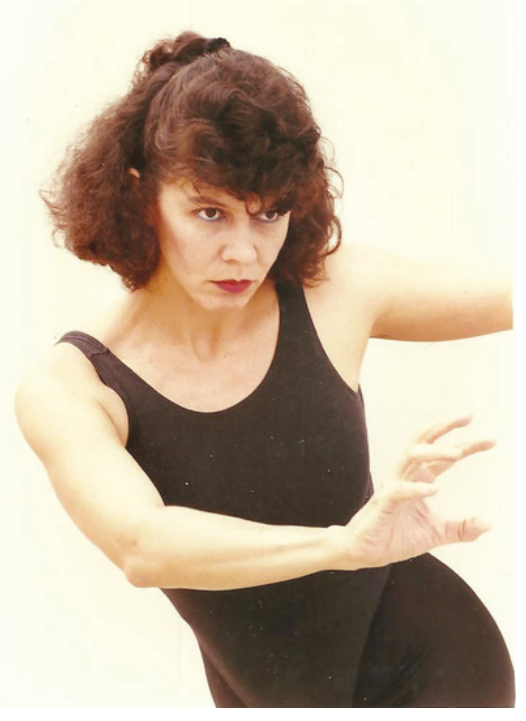

Fuente: Archivo de la autora

En Tegucigalpa fue miembro del Teatro Infantil de Honduras, bailarina de la Compañía Nacional de Danza, bailarina del grupo independiente Danza Renacer, miembro fundadora, bailarina, maestra y coreógrafa de la Fundación y Escuela Danza Libre, miembro fundadora de Arte Acción y maestra de la Escuela Nacional de Danza Mercedes Agurcia Membreño.
En Costa Rica fue bailarina y asistente de dirección de la Compañía de Cámara Danza UNA, maestra y coreógrafa del grupo Sembrando Futuro; directora y maestra de su academia Danza Studio. 
Fotografía 15.

Compañía de Cámara Danza UNA.

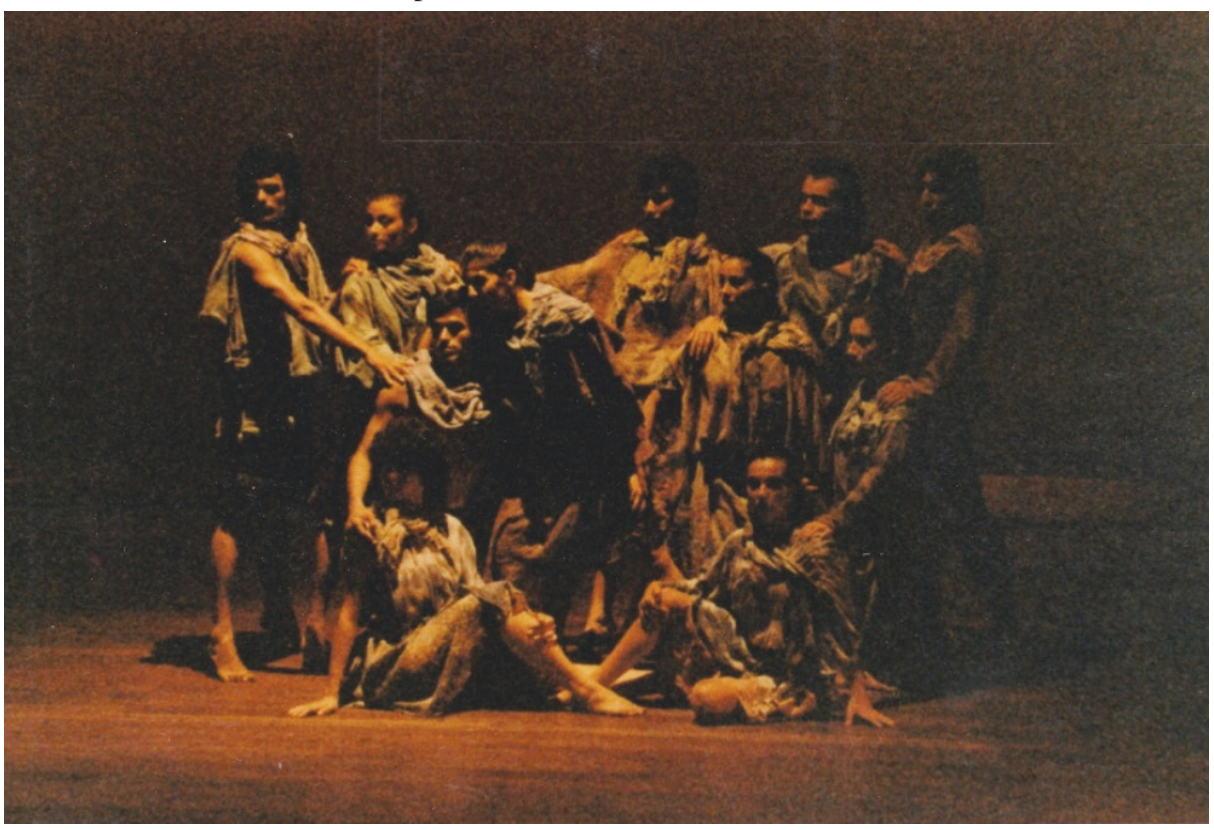

Fuente: Archivo de la autora

En San Pedro Sula, fue directora y maestra por cinco años del Centro Cultural Infantil financiado por el gobierno municipal.

Sus experiencias más sobresalientes son un montaje para la toma de posesión del ex-presidente Ricardo Maduro, presentado en Copán Ruinas; el Certamen Infantil de Ballet, Centroamérica y el
Caribe en Mérida, en el que fue jurado calificador; el Taller de Contemporáneo que impartió para alumnos avanzados de la Escuela Nacional de Danza Morena Celarie en El Salvador; y la coordinación artística de Bailando por un Sueño 2010. 
Fotografía 16.

Toma de posesión del expresidente Ricardo Maduro. Copán Ruinas.

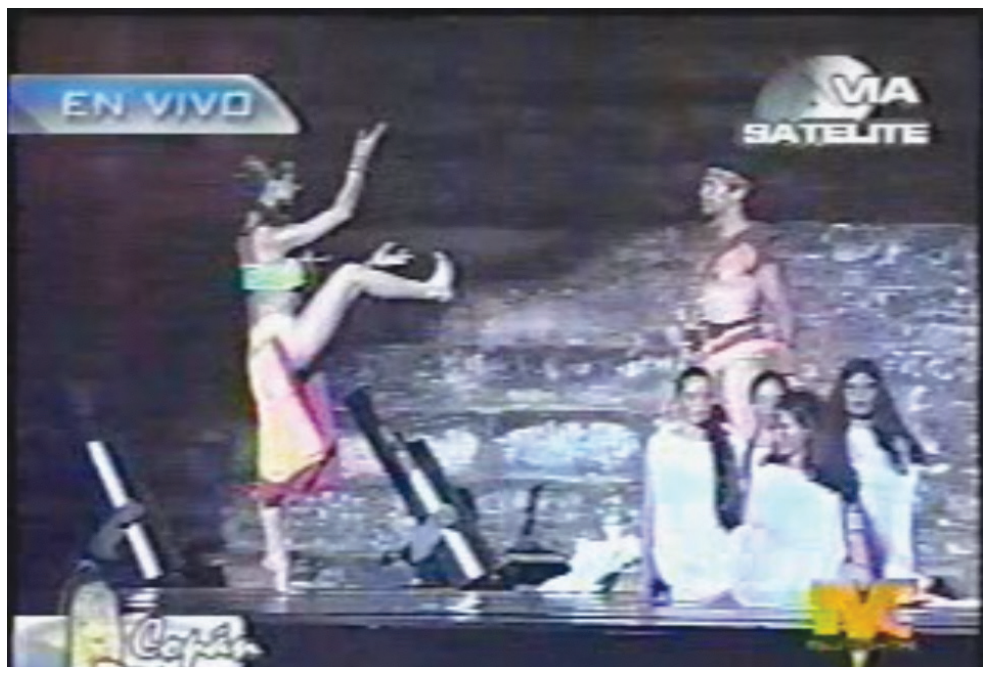

Fuente: Archivo de la autora

Ha recibido los siguientes reconocimientos

- En 1985, tuvo el mejor promedio del Centro de investigación en docencia y extensión artística (CIDEA)

- 2005, Creatividad, Bussines Software Alliance En el 2005, tuvo el premio de Creatividad, en el Business Software Alliance

- En el 2014, recibió la Hoja de Laurel en Oro, del Ministerio de Cultura, Artes y Deportes de Honduras

En Siguatepeque ha sido directora de sus academias Danza Estudio Sigua y en la actualidad Estudio Danzarte. En los últimos años ha recibido ocho capacitaciones del método de la Royal Academy of Dance, en San Pedro Sula, Costa Rica y Guatemala, con las maestras Flor Alvergue, Wendy Green, Ildana Contreras y Ana Jurado.

\section{Danza académica en Siguatepeque}

Siguatepeque es una ciudad relativamente joven, constituida como tal en 1926. Está ubicada en un altiplano en el departamento de Comayagua, en la zona central de Honduras, casi de manera equidistante con las dos ciudades principales del país: Tegucigalpa y San Pedro Sula.

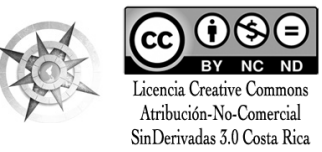


La danza académica en Siguatepeque inicia con la apertura de la academia Danza Estudio Sigua, bajo la dirección de Sara Buck, en 1989, donde se impartían clases de Ballet Clásico y Danza Contemporánea. Durante ese periodo se realizan estrenos anuales y presentaciones a solicitud de diversas instituciones públicas y privadas, en diferentes locaciones de la ciudad.

\section{Fotografía 17.}

Danza Estudio Sigua.

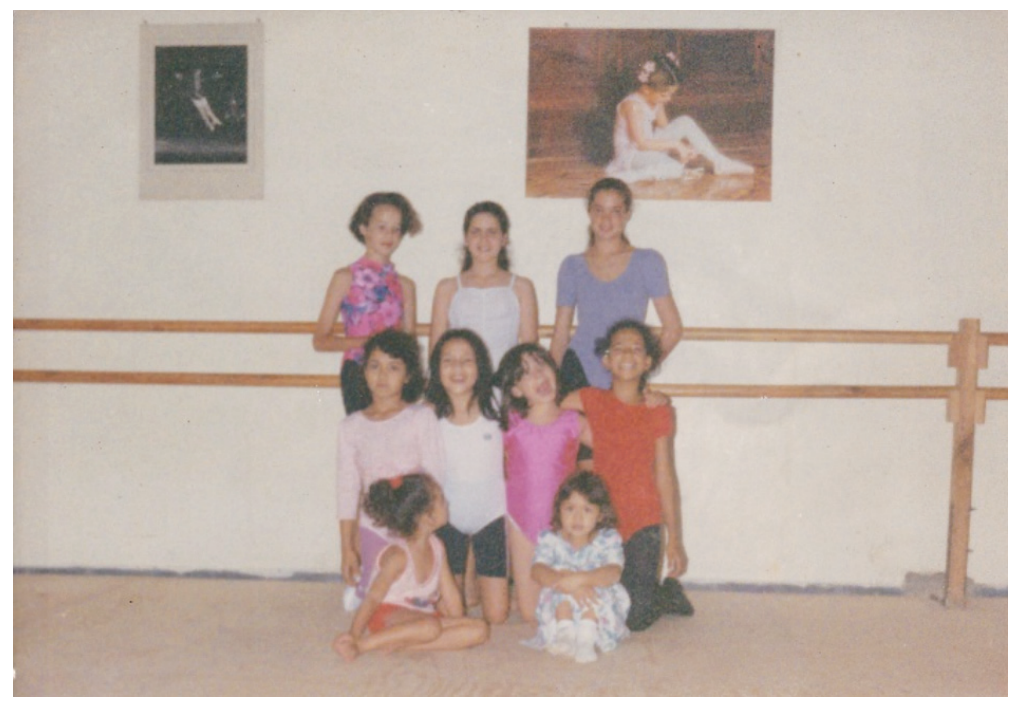

Fuente: Archivo de la autora

El ambiente no era nada propicio, gran parte de la población había tenido poco contacto con el ballet clásico y desconocía por completo la danza contemporánea o tenía un concepto equivocado sobre la misma, confundiéndola con la danza popular. Era curioso que al presentar las coreografías el público se quedara estupefacto, sin reacción alguna. Fue un proceso el que llegaran a aplaudir como una manifestación ante lo presenciado.

Poco a poco el público comienza a disfrutar de las propuestas artísticas, a pesar de no contar con las condiciones idóneas de un teatro ni una casa de la cultura. Los estrenos de obras eran presentados en el Gimnasio del Instituto Oficial Genaro Muñoz Hernández, con 
la dificultad de tener que instalar, además de la escenografía, la iluminación y los telones para dar un marco adecuado al espectáculo.

Las condiciones difíciles de la ciudad obligaron a su cierre en el año 1995, pero casi de manera simultánea la Escuela de Ballet Dilcia Mejía abre sus puertas, enseñando Ballet Clásico y se mantiene funcionando hasta el año 1997, año en que se traslada a la ciudad de Comayagua.

\section{Estudio Danzarte (academia privada, 2008-actualidad)}

Bajo la dirección de Sara Buck, Estudio Danzarte inicia sus labores en 2008, con el fin de ofrecer un espacio de desarrollo para la niñez y juventud de la ciudad a través de una enseñanza de calidad en distintos géneros de danza académica.

Actualmente, Estudio Danzarte imparte Ballet Clásico, Danza Contemporánea, Tap, Danza Árabe y Yoga, y dependiendo del nivel, cada alumna recibe mínimo dos horas semanales.

Fotografía 18.

Estudio Danzarte.

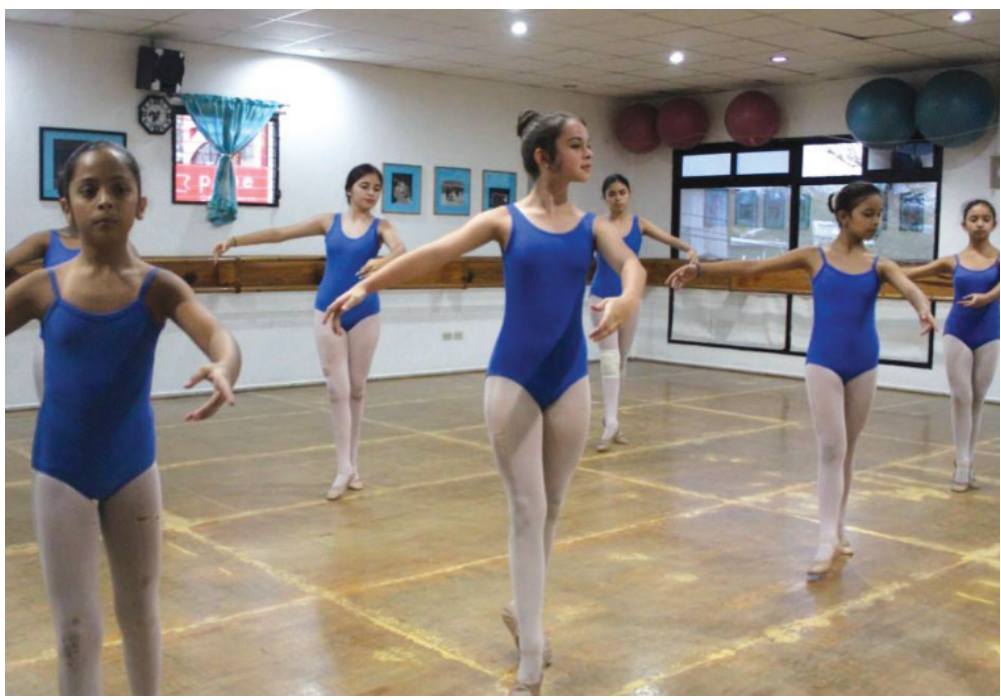


La academia realiza clases abiertas dos veces al año. Esta es una actividad muy importante para la institución, pues es el momento en donde los padres, familiares y amistades de las alumnas conocen de cerca el proceso de formación de un bailarín y pueden constatar el amplio rango de beneficios que la danza ofrece.

Para mostrar los avances de las alumnas y a manera de clausura, cada año, se realiza el montaje de un espectáculo nuevo. Las temáticas han sido variadas; se han hecho espectáculos en torno a una idea central, otros basados en cuentos de la literatura universal infantil y otros basados en ballets clásicos. El alumna- do va en aumento cada año y en 2016 participaron 115 alumnas e invitados.

Estudio Danzarte ha realizado intercambios con instituciones del país como CCDanza de San Pedro Sula, Allegro Dance Roatán y Danza Libre de Tegucigalpa. Dichos intercambios han consistido en Talleres de Ballet y Contemporáneo y la realización de presentaciones. Eventualmente, ha contado con maestros invitados como Nandayure Harley y Leo Aguirre (Costa Rica), Janine Montag (Estados Unidos.), Sandra Gómez (Nicaragua), Magda Musa (Suecia), Martha Castellón (El Salvador) y Josué Pio Pio (Guatemala).

Fotografía 20.

Intercambio Allegro Dance Roatán - Estudio Danzarte.

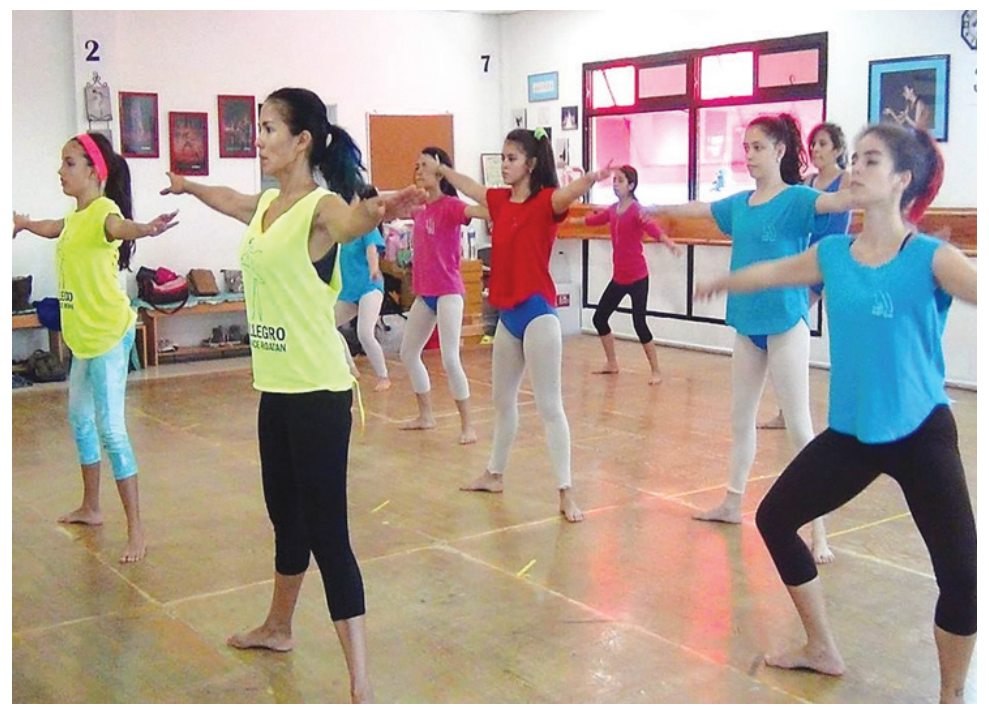

Fuente: Archivo de la autora

(C)

96 La danza académica en Honduras Sara Buck- Rodríguez

Licencia Creative Commons Atribución-No-Comercial SinDerivadas 3.0 Costa Rica 
Además de maestros de danza invitados, Estudio Danzarte ha querido complementar la danza con teatro, ofreciendo talleres, de acuerdo a la edad, los cuales han sido impartidos por Fredy Ponce y han ayudado en las capacidades interpretativas de las alumnas.

\section{Eventos locales y nacionales}

La academia participa anualmente en importantes eventos locales, como el Festival Nacional del Pino y el Fes- tival de las Flores; ha participado en eventos nacionales como el Festival Gracias Convoca y el II Encuentro de Escuelas en Tegucigalpa, además realiza presentaciones a nivel local y nacional como proyección artística, a solicitud de diversas instituciones, tanto públicas como privadas, presentándose en universidades, colegios, centros comerciales, plazas, parques, restaurantes, salones de eventos, canales locales de televisión, etc.

Fotografía 21.

Presentación artística de la academia.

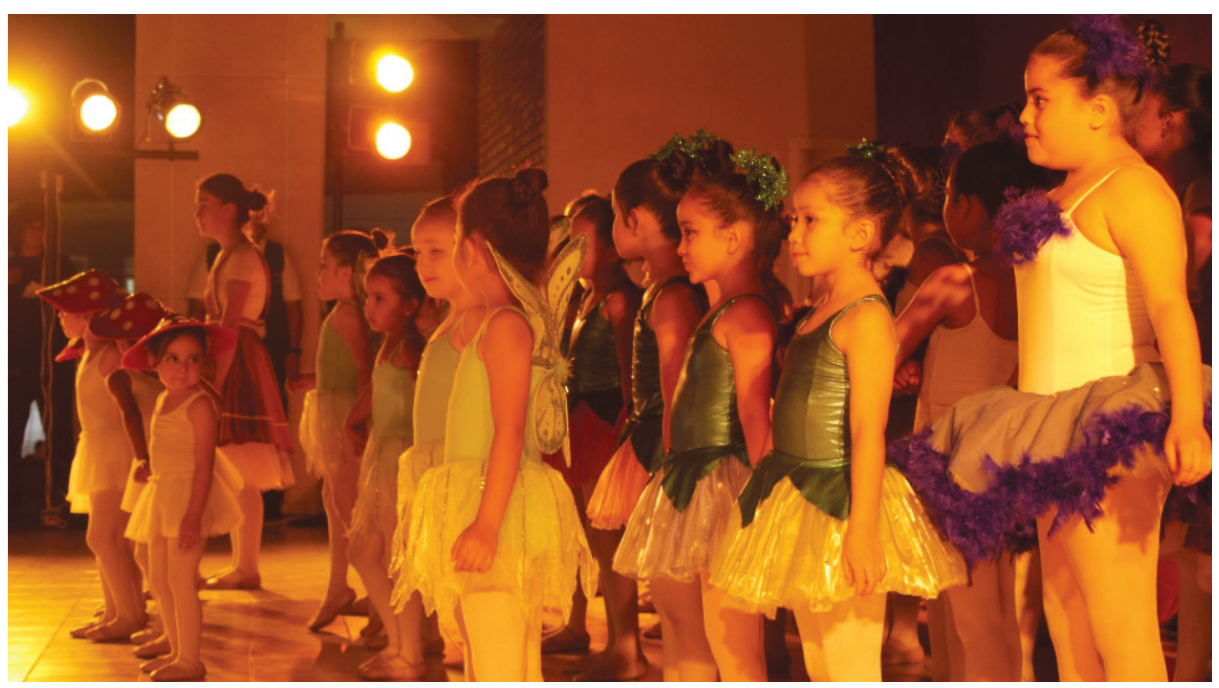

Fuente: Archivo de la autora 
Fotografía 22.

Presentación artística de la academia.

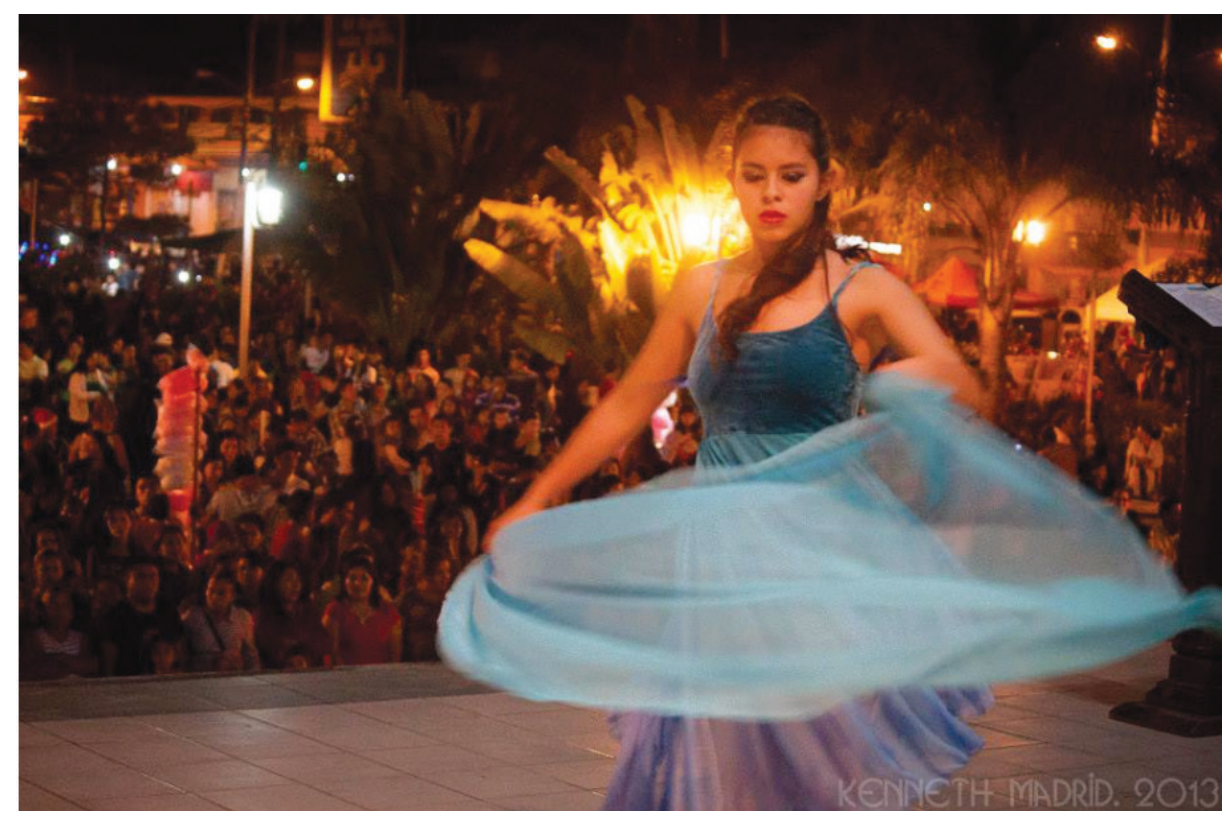

Fuente:

Ha promovido eventos con grupos de danza extranjeros, el primero Danza en la Mira, Festival Centroamericano y el segundo organizado por el área de danza del Departamento de Arte de la UNAH con la Compañía de Cámara Danza UNA de Costa Rica. Ambos consistieron en talleres y presentación de espectáculos abiertos al público en general. 
Fotografía 23.

Danza en la Mira.

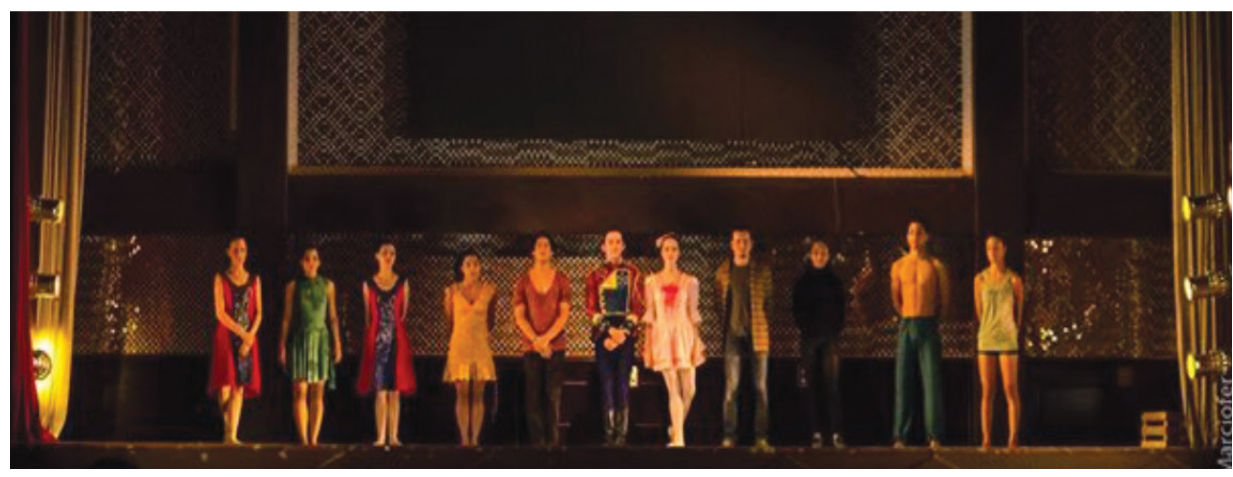

Fuente: Archivo de la autora

Fotografía 24.

Taller con la maestra Nandayure Harley.

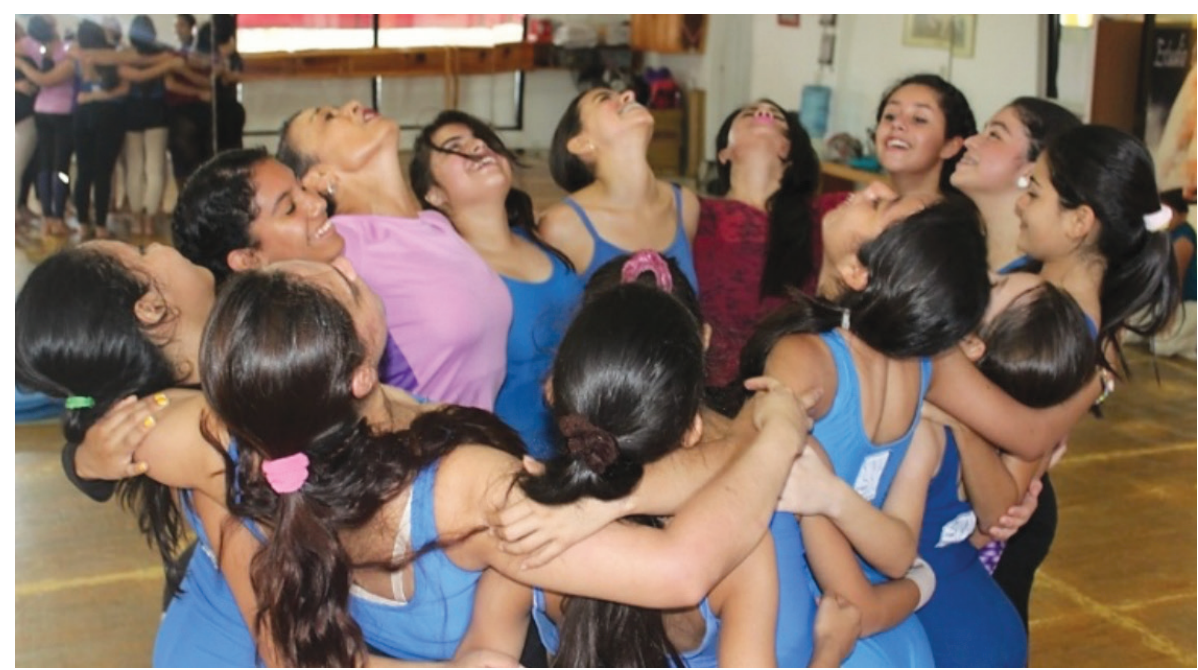

Fuente: Archivo de la autora 


\section{Fotografía 25:}

Compañía de Cámara Danza UNA.

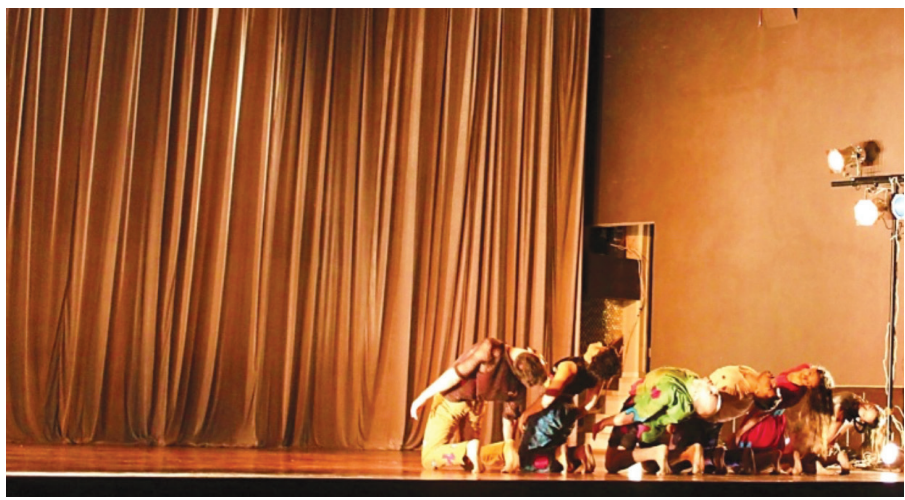

Fuente: Archivo de la autora

Estudio Danzarte cuenta con un programa ayuda para alumnas de pocos recursos económicos que pueden ser media beca o beca completa (exoneración parcial o total del pago), con el fin de dar oportunidad a más niñas y jóvenes.

\section{Metodología}

En el área de ballet clásico, Estudio Danzarte aplica la metodología de la Royal Academy of Dance, bajo la tutoría de la maestra certificada Flor Alvergue, directora de CCDanza, de San Pedro Sula.

Fotografía 26.

Evaluations Royal Academy of Dance.

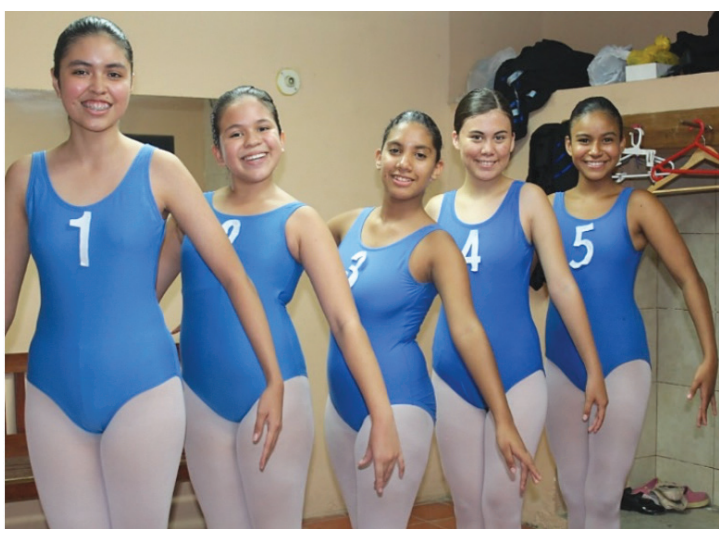

Fuente: Archivo de la autora

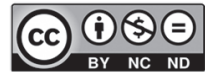

Licencia Creative Commons Atribución-No-Comercial

100 La danza académica en Honduras Sara Buck- Rodríguez

SinDerivadas 3.0 Costa Rica

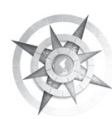


Se manejan nueve niveles diferentes con niñas de 3 años en adelante. Según el nivel, las alumnas reciben dos o más horas semanales de clases. En cierta etapa del año se realiza un proceso de selección para definir quiénes son aptas para evaluaciones RAD. Durante tres años consecutivos nuestras alumnas han sido evaluadas en la academia de Flor Alvergue por las examinadoras internacionales certificadas de RAD, obteniendo excelentes calificaciones que constan en diplomas reconocidos a nivel mundial.

Fotografía 27.

Entrega de diplomas RAD.

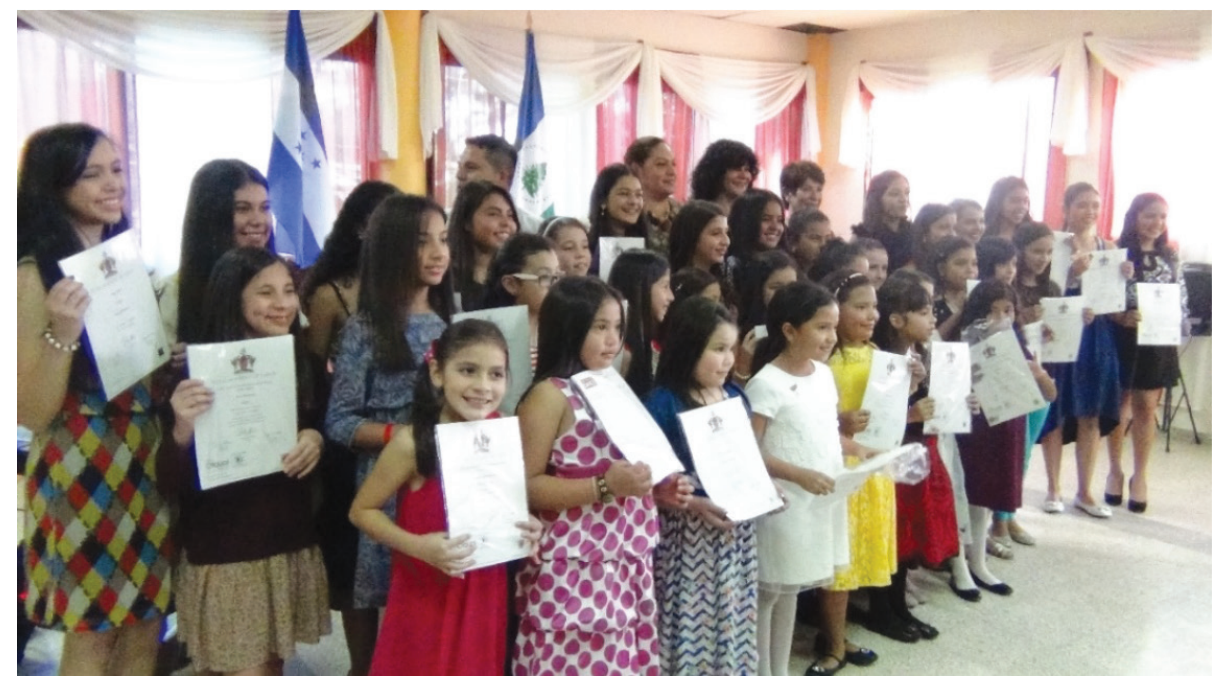

A nivel de danza contemporánea, se imparten técnicas basadas en Graham, Limón y Cunningham y en las áreas de tap y danza árabe se usan técnicas mixtas.

\section{Estudio Danzarte baluarte de Siguatepeque}

Estudio Danzarte ha sido la institución de danza representativa de Siguatepe- que por diez años. Muchas alumnas y muchos alumnos han pasado por esta institución. La danza clásica, la contemporánea y el tap han sido conocidos por los pobladores de Siguatepeque gracias a la labor y proyección de Estudio Danzarte.

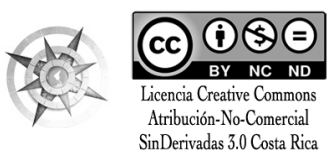


Fotografía 28.

Público asistente a los espectáculos de Estudio Danzarte.

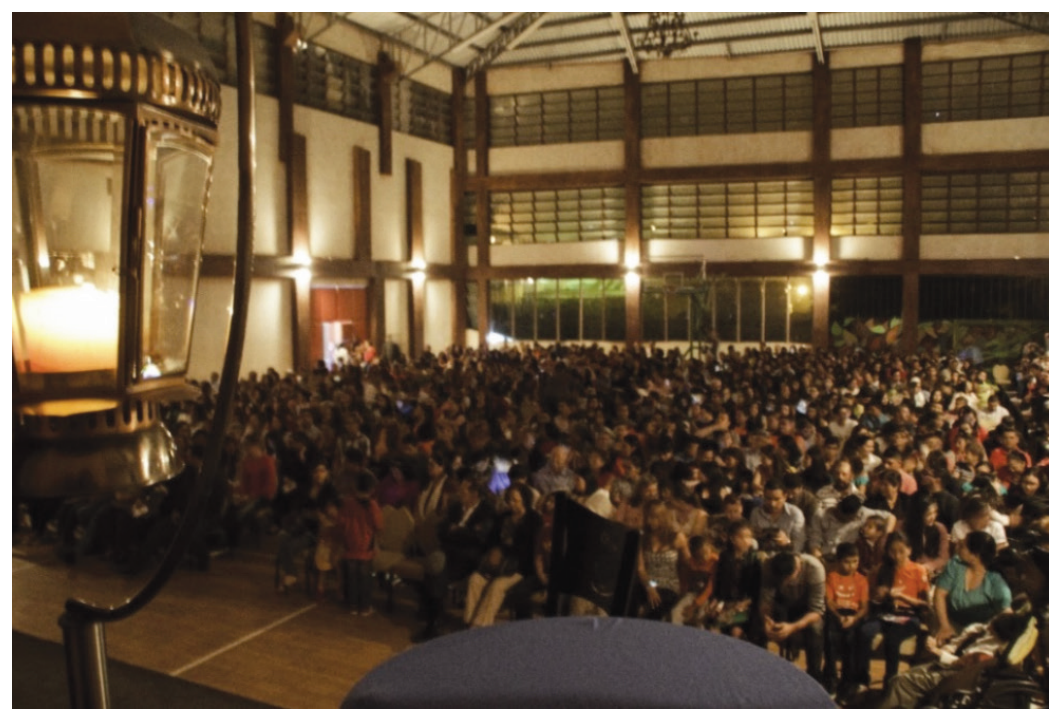

Fuente: Archivo de la autora

La comunidad se ve involucrada y se beneficia en varios niveles.

- Las alumnas reciben el beneficio de la formación en Danza, además de los beneficios físicos, mentales y emocionales que la danza implica.

- Los padres, familiares y amigos se van integrando al proceso y tomando conciencia de los beneficios que reciben sus hijas.

- Para poder montar los espectáculos, Estudio Danzarte se ha visto en la necesidad de capacitar técnicos en iluminación, escenografía y tramoya, lo cual ha significado una oportunidad de capacitación y trabajo eventual para las personas involucradas.

- También para el proceso del espectáculo Estudio Danzarte ofrece oportunidad de trabajo eventual, nuevos retos y aprendizaje a varias modistas que se encargan de confeccionar el vestuario necesario.

- El público tiene un espacio para disfrutar de la danza y va ampliando sus criterios de apreciación artística. Cada año el gusto por el arte va creciendo, igual que la exigencia de calidad y frecuencia de presentaciones y los espectáculos de danza son cada vez más concurridos.

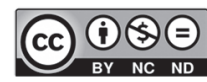

Licencia Creative Commons Atribución-No-Comercial SinDerivadas 3.0 Costa Rica

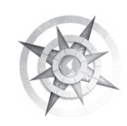




\section{La danza como herramienta de desarrollo individual}

En treinta y cinco años que llevamos en el mundo de la danza, cada día constatamos que realmente aporta algo especial a quien la práctica, que no puede adquirir en la educación formal.

Nuestra sociedad no ha evolucionado de manera integral. Quienes han gobernado el destino de nuestro pueblo han desperdiciado el arte como una fuerte herramienta que potencia al individuo y lo conduce a una realización plena, en donde es tan importante el desarrollo material como el anímico.

El arte cambia la apreciación que tiene un individuo sobre su persona, lo hace confiar en que puede cultivar capacidades y le hace creer en sí mismo. Esa es la base de la realización de un individuo y el individuo es la plataforma sobre la que se desarrolla la sociedad.

Dentro de los beneficios de practicar danzas académicas, están los físicos: Huesos y músculos sanos y fuertes, más capacidad del corazón y de los pulmones, eliminación de toxinas a través de la sudoración, gracia y control del cuerpo, figura equilibrada, organismo enérgico y activo, facilidad de aprender otras disciplina físicas y destrezas físicas, como flexibilidad, agilidad, coordinación, resistencia, equilibrio, rapidez.

Dentro de los beneficios mentales, están retención de indicaciones en la mente, vocabulario dancístico y artístico, capacidad de seguir instrucciones, velocidad y agilidad mental, desarrollo de los dos lóbulos del cerebro, imaginación y creatividad, concentración, sentido espacial, Coordinación y observación

Como parte de los beneficios emocionales de practicar el ballet, están las nuevas y emotivas relaciones sociales, la expresión de sentimientos y emociones, la relajación física y mental, la confianza en sí mismo, el placer y satisfacción, el aprecio por las artes, la autoestima

\section{Conclusiones}

Si bien las condiciones socioeconómicas y culturales de nuestro país no permiten mayor desarrollo de las danzas académicas, es patente que la danza sigue y seguirá siendo un medio de expresión inherente e indispensable del ser humano y cada día son más las personas amantes de la danza en sus diferentes manifestaciones.

Creemos firmemente que la danza como medio de expresión artística es un instrumento valioso a través del cual todo ser humano puede expresar sus 
sentimientos e inquietudes más profundas. No importa cuál de todas las manifestaciones prefiera, todas ellas son válidas para ejercitar el cuerpo, liberar emociones, relajar la mente y comunicarse con los demás seres humanos.

La danza en nuestro país, similar que otras disciplinas artísticas, ha alcanzado un alto nivel a pesar de las condiciones desfavorables para su desarrollo. Poco a poco se va incrementando una cultura de ver, practicar, usar, pagar, desarrollar y disfrutar el arte.

Afirmamos con certeza que el arte hace mejores sociedades. 